

\section{COMPETENCIAS DEL SIGLO XXI: ¿CÓMO DESARROLLARLAS MEDIANTE EL USO DE VIDEOJUEGOS EN UN CONTEXTO MULTIGRADO?

\section{1st century competencies: how to develop them through the use of video games in a multigrade context?}

Competências do século xxi: como desenvolvê-las através do uso de videogames em um contexto multigrau?

\section{RECIBIDO: 5 MARZO 2017}

Yennis Cristina Lozano Abad

Licenciada en Informática Educativa y

Medios Audiovisuales de la Universidad

de Córdoba. Docente de Tecnología e

Informática de la Institución Educativa El

Cerrito, de Montería, Córdoba. Candidata

a Magíster de la Maestría en Educa-

ción SUE-Caribe, de la Universidad de

Córdoba.

yennislo@hotmail.com

\section{es}

\section{Resumen}

El siglo XXI trae consigo la necesidad de desarrollar competencias que permitan a las personas convertirse en trabajadores y ciudadanos efectivos; es decir, competencias del siglo XXI (Ananiadou, 2010; ATC21S, 2015). Los videojuegos, como primera tecnología informática a la cual un gran número de personas tuvo un acceso directo y personal (Levis, 2013), resultan un medio atractivo para desarrollar diferentes habilidades, por lo tanto podrían convertirse en un recurso idóneo para desarrollar competencias del siglo XXI y enriquecer ambientes de aprendizaje, especialmente en entornos de formación multigrado, donde las características de los estudiantes hace necesario implementar propuestas pedagógicas innovadoras, activas $y$ participativas, lo que conlleva a construir una propuesta educativa desde las experiencias en el quehacer pedagógico, que fomente el desarrollo de competencias del siglo XXI a partir del uso de videojuegos, esto buscando generar iniciativas que permitan guiar a los docentes de sedes multigrado, creando una oportunidad para que estos identifiquen cómo desarrollar competencias con estrategias que pueden ser viables y que hayan sido probadas en un contexto real y con un proceso organizado y planeado.

Palabras clave: Videojuegos, competencias, multigrado, tecnología, estrategia.

\section{EVALUADO: 12 MAYO 2017 10 AGOSTO 2017 3 OCTUBRE 2017}

Angélica María Rosales Doria Licenciada en Informática Educativa y Medios Audiovisuales de la Universidad de Córdoba. Docente de Básica Primaria de la Institución Educativa Mariscal Sucre, del municipio de Buenavista, Córdoba. Candidata a Magíster de la Maestría en Educación SUE-Caribe, de la Universidad de Córdoba.

angeemariarosalesdoria@hotmail.com

\section{Abstract}

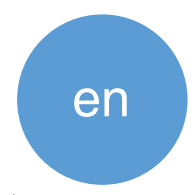

The 21st century brings with it the need to develop skills that enable people to become effective workers and citizens, i.e. 21st century skills (Ananiadou, 2010; ATC21S, 2015). Video games as the first computer technology to which a large number of people had direct and personal access (Levis, 2013) are an attractive means to develop different skills, therefore could become an ideal resource to develop skills of the twenty-first century and enrich learning environments especially in multigrade training environments where the characteristics of students makes it necessary to implement innovative pedagogical proposals, active and participative, which leads to building an educational proposal based on experiences in pedagogical work that fosters the development of 21st century competencies from the use of video games, this seeking to generate initiatives to guide teachers in multigrade sites, creating an opportunity for them to identify how to develop competencies with strategies that can be viable and that have been tested in a real context and with an organized and planned process.

Keywords: Video games, competences, multigrade, technology, strategy
APROBADO: 10 ENERO 2018

Juan Carlos Giraldo Cardozo Licenciado en Matemáticas y Computación de la Universidad del Quindío. Especialista de la Universidad E1 Bosque en Pedagogía del Lenguaje Audiovisual. Magíster de la Universidad del Valle en Ingeniería de Sistemas y Computación. Docente de tiempo completo del Departamento de Informática Educativa de la Facultad de Educación en la Universidad de Córdoba y la Maestría en Educación del SUE Caribe.

jgiraldo@correo.unicordoba.edu.co

\section{Resumo}

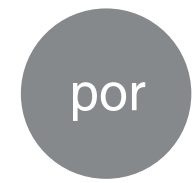

O século XXI traz consigo a necessidade de desenvolver competências que permitam às pessoas tornarem-se trabalhadores e cidadãos eficazes, ou seja, competências do século XXI (Ananiadou, 2010; ATC21S, 2015). Jogos de vídeo, como a primeira tecnologia de computador para a qual um grande número de pessoas tinha acesso directo e pessoal (Levis, 2013), são um meio atraente de desenvolver diferentes habilidades, e poderia, portanto, tornar-se um recurso ideal para desenvolver habilidades do século 21 e enriquecer os ambientes de aprendizagem, especialmente em ambientes de formação multigrau, onde as características dos alunos tornam necessário implementar propostas pedagógicas inovadoras, Ativo e participativo, que leva à construção de uma proposta educativa a partir de experiências de trabalho pedagógico, que promove o desenvolvimento de habilidades do século XXI a partir do uso de jogos de vídeo, este buscando gerar iniciativas para orientar os professores em locais multigrau, criando uma oportunidade para que eles possam identificar como desenvolver habilidades com estratégias que podem ser viáveis e foram testados em um contexto real e com um processo organizado e planejado.

Palavras-Chave: Jogos de vídeo, competições, multigrau, tecnologia, estratégia.

\section{Para citar este articulo / to cite this article / para citar este artigo:}


Yennis Cristina Lozano

Abad I

Angélica María Rosales Doria I

Juan Carlos Giraldo Cardozo I

Panorama I

pp. 7-17।

Volumen 12 I

Número 231

Julio - Diciembre I

2018 I

ISSN Impreso 1909-7433 I

ISSN en línea 2145-308X I

\section{INTRODUCCIÓN}

El siglo XXI viene con nuevas tendencias, transformaciones y la necesidad de desarrollar competencias que permitan a las personas convertirse en trabajadores efectivos, en personas que tengan la capacidad de asumir cambios y adaptarse a diferentes contextos, generar ideas originales y pertinentes, comunicarse de forma efectiva y eficaz, producir utilizando las tecnologías como herramientas, plantear y fijarse metas, sortear obstáculos, interpretar, analizar, hacer inferencias, trabajar de forma efectiva con otras personas para alcanzar un objetivo en común y autorregular su propio proceso de aprendizaje, es decir, competencias del siglo XXI (Ananiadou, 2010; ATC21S, 2015). Cabe resaltar que es deber de la educación aportar y utilizar los medios para desarrollar las habilidades que permiten a los estudiantes asumir los cambios a los cuales se encuentran inmersos en este siglo (Ministerio de Educación Nacional de Colombia, 2015; Ley 115, 1994). Igualmente, esta época está enmarcada por las tecnologías de la información y la comunicación (TIC), lo que conlleva a que su uso se haya convertido en un hábito cotidiano que permea en todos los ámbitos de la sociedad, desde la relaciones interpersonales por medio de las redes sociales, hasta el uso de aplicaciones para acceder a diferentes servicios como compras, búsqueda de información, acceso al mercado laboral, formas de entretenimiento y diversos trámites.

Los videojuegos, como primera tecnología informática a la cual un gran número de personas tuvo un acceso directo y personal (Levis, 2013), resultan un medio atractivo para desarrollar habilidades sociales, habilidades para la resolución de problemas, planificación de estrategias, toma de decisiones, búsqueda de información, colaboración en grupo, descubrimiento inductivo, razonamiento lógico, autocontrol, competencias TIC, entre otras (Gee, 2004; Ferrer, 2005; Gómez del Castillo, 2007; Morales, 2009), lo que demuestra que podrían convertirse en un recurso idóneo para desarrollar competencias del siglo XXI y enriquecer ambientes de aprendizaje, especialmente en entornos de formación multigrado donde es necesario cambiar las prácticas tradicionales de enseñanza, manejar la heterogeneidad del aula, introducir el aprendizaje cooperativo y desarrollar estrategias flexibles (Colbert, 1999). Es preciso anotar que un entorno de formación multigrado es aquel en donde en una misma aula de clase se agrupan estudiantes de dos o más grados que son atendidos por un único docente; esta modalidad educativa es propia de las zonas rurales (Bustos, 2010).

Actualmente es común que los niños y jóvenes tengan acceso a dispositivos electrónicos, tanto en sus hogares como en las instituciones educativas a las que asisten diariamente. Sin embargo, en las sedes multigrado Villa Aideé, Veracruz, Campo Solo y El Paraíso, adscritas a la Institución Educativa Mariscal Sucre de Buenavista, Córdoba, en donde se realizó la investigación "Construcción colaborativa de una metodología para el uso de videojuegos que aporten al desarrollo de las competencias del siglo XXI en un contexto de formación multigrado (VICOM S-21)", el uso de estos dispositivos era ocasional o nulo, pues los docentes de estas sedes multigrado no tenían un derrotero a seguir que les permitiera implementar o crear estrategias para el uso adecuado de TIC y el desarrollo de competencias.

Considerando que es necesario formar personas competentes para el mundo actual, y teniendo en cuenta que los videojuegos pueden ser una opción para el desarrollo de competencias, por sus características propias: al jugar con ellos los niños tienen libertad de actuación; tienen metas y propósitos específicos que deben alcanzar, para lo cual ponen en práctica múltiples mecanismos y recursos; por medio de su narrativa hacen al niño participe de una historia compleja de relaciones sociales reales e imaginarias, e incluso hacen que las construya; permiten que el niño experimente con diferentes opciones de juego; se adaptan a las capacidades de aprendizaje de cada estudiante; dinamizan sus relaciones de grupo y su conducta, y hacen al jugador el centro de la experiencia, por lo cual este debe concentrarse y focalizar su interés (Eguia, 2012), y observando que las sedes multigrado adscritas a la Institución Educativa Mariscal Sucre poseen los recursos tecnológicos necesarios, se construyó desde las experiencias en el quehacer pedagógico una metodología que fomenta el desarrollo de competencias del siglo XXI a partir del uso de videojuegos en un contexto de formación multigrado; lo anterior, buscando generar iniciativas que permitan guiar a los docentes de sedes multigrado, creando una 
oportunidad para que estos identifiquen cómo desarrollar competencias con estrategias que pueden ser viables y que hayan sido probadas en un contexto real y con un proceso organizado y planeado.

\section{DISEÑO METOdOLÓGICO}

La investigación construcción colaborativa de una metodología para el uso de videojuegos que aporten al desarrollo de las competencias del siglo XXI en un contexto de formación multigrado (VICOM S-21), fue realizada con todos los estudiantes y docentes de las sedes multigrado de la Institución Educativa Mariscal Sucre del municipio de Buenavista, Córdoba (Villa Aideé, Campo Solo, El Paraíso y Veracruz). El tipo de estudio utilizado fue la investigación acción, pues los docentes de estas sedes reflexionaron acerca de sus prácticas de aula, analizaron los beneficios pedagógicos de los videojuegos -al ser utilizados con una intencionalidad educativa- $y$ la necesidad de desarrollar competencias del siglo XXI en sus estudiantes, y a partir de allí crearon estrategias que permitieron la construcción de una propuesta educativa; además, se validó mediante la observación y análisis si al introducir la metodología VICOM-S21 en el quehacer académico de los estudiantes se desarrollan estas competencias. Este estudio se basó en el modelo de investigación acción de Kemmis, constituido por cuatro fases integradas: planificación, acción, observación y reflexión, formando estas una espiral autorreflexiva de conocimiento y acción. La fase de reflexión es la que finaliza cada ciclo y es base para la elaboración del informe y de un posible replanteamiento de las estrategias para iniciar el siguiente ciclo (Latorre, 2007).

El proceso investigativo tuvo una duración de 13 meses, se desarrolló en tres ciclos, cada uno relacionado con un objetivo específico, como se muestra en la siguiente tabla:
Tabla 1. Relación objetivos específicos - ciclos de la investigación

\begin{tabular}{|l|l|l|}
\hline No. & \multicolumn{1}{|c|}{ Nombre del ciclo } & \multicolumn{1}{c|}{ Objetivo } \\
\hline 1 & $\begin{array}{l}\text { Propuesta de acciones } \\
\text { y estrategias }\end{array}$ & $\begin{array}{l}\text { Proponer estrategias y acciones que } \\
\text { involucren el uso de videojuegos en } \\
\text { el aula de clases para potenciar las } \\
\text { competencias del siglo XXI en un } \\
\text { contexto de formación multigrado. }\end{array}$ \\
\hline 2 & $\begin{array}{l}\text { Formalización y } \\
\text { aplicación }\end{array}$ & $\begin{array}{l}\text { Formalizar y aplicar una metodología } \\
\text { basada en el uso de videojuegos que } \\
\text { potencie competencias del siglo XXI. }\end{array}$ \\
\hline 3 & Retroalimentación & $\begin{array}{l}\text { Analizar los cambios, ventajas y } \\
\text { limitaciones que se evidencian en } \\
\text { la utilización de la metodología } \\
\text { propuesta. }\end{array}$ \\
\hline
\end{tabular}

Fuente: elaboración propia (2018)

Es preciso resaltar que antes de iniciar los ciclos se establece una idea o tema del cual se parte para realizar el estudio: ¿Qué orientaciones metodológicas pueden derivarse, a partir del uso de videojuegos, para desarrollar competencias del siglo XXI, desde el quehacer pedagógico en un contexto de formación multigrado? En cada ciclo se implementaron cuatro fases denominadas planeación, acción, observación y reflexión, como se muestra en las siguientes tablas.

Tabla 2. Proceso investigativo: propuesta de acciones y estrategias Ciclo 1: Propuesta de Acciones y Estrategias

\begin{tabular}{|c|c|c|c|}
\hline Fase & Acciones & $\begin{array}{l}\text { Técnica de } \\
\text { investigación }\end{array}$ & Tiempo \\
\hline \multirow{4}{*}{ Planeación } & $\begin{array}{l}\text { Escoger la población } \\
\text { participante }\end{array}$ & Observación & \multirow{4}{*}{45 días } \\
\hline & Revisión de literatura & $\begin{array}{l}\text { Gestión } \\
\text { documental }\end{array}$ & \\
\hline & $\begin{array}{l}\text { Codificación de los } \\
\text { docentes }\end{array}$ & $\begin{array}{l}\text { Gestión } \\
\text { documental }\end{array}$ & \\
\hline & $\begin{array}{l}\text { Elaboración de } \\
\text { cuestionario para } \\
\text { primer acercamiento }\end{array}$ & $\begin{array}{l}\text { Diseño de } \\
\text { instrumentos }\end{array}$ & \\
\hline \multirow{3}{*}{ Acción } & $\begin{array}{l}\text { Actividad 1: primer } \\
\text { acercamiento }\end{array}$ & $\begin{array}{l}\text { Entrevista } \\
\text { semiestructurada }\end{array}$ & \multirow{3}{*}{30 días } \\
\hline & $\begin{array}{l}\text { Actividad 2: } \\
\text { conversatorio }\end{array}$ & Grupo Focal & \\
\hline & $\begin{array}{l}\text { Actividad 3: reunión } \\
\text { cierre de fase }\end{array}$ & $\begin{array}{l}\text { Entrevista } \\
\text { semiestructurada }\end{array}$ & \\
\hline \multirow{3}{*}{$\begin{array}{l}\text { Observa- } \\
\text { ción }\end{array}$} & $\begin{array}{l}\text { Actividad 1: primer } \\
\text { acercamiento }\end{array}$ & $\begin{array}{l}\text { Entrevista } \\
\text { semiestructurada }\end{array}$ & \multirow{3}{*}{30 días } \\
\hline & $\begin{array}{l}\text { Actividad 2: } \\
\text { conversatorio }\end{array}$ & Grupo Focal & \\
\hline & $\begin{array}{l}\text { Actividad 3: reunión } \\
\text { cierre de fase }\end{array}$ & $\begin{array}{l}\text { Entrevista } \\
\text { semiestructurada }\end{array}$ & \\
\hline \multirow{4}{*}{ Reflexión } & $\begin{array}{l}\text { Análisis de la } \\
\text { información }\end{array}$ & \multirow{4}{*}{ Diálogo reflexivo } & \multirow{4}{*}{30 días } \\
\hline & $\begin{array}{l}\text { Contrastación de } \\
\text { teorías }\end{array}$ & & \\
\hline & $\begin{array}{l}\text { Discusión grupo } \\
\text { coinvestigador }\end{array}$ & & \\
\hline & $\begin{array}{l}\text { Diseño metodología } \\
\text { VICOM S- } 21 .\end{array}$ & & \\
\hline
\end{tabular}

I Panorama

I pp. 7-17

I Volumen 12 I Número 23 I Julio - Diciembre I 2018
Competencias del siglo XXI: ¿cómo desarrollarlas mediante el uso de videojuegos en un contexto multigrado? 


\begin{tabular}{|c|c|c|c|c|}
\hline Yennis Cristina Lozano & \multirow[b]{2}{*}{ Planeación } & $\begin{array}{l}\text { Selección de } \\
\text { videojuegos }\end{array}$ & $\begin{array}{l}\text { Selección por } \\
\text { conveniencia }\end{array}$ & \multirow[b]{2}{*}{15 días } \\
\hline \multirow{2}{*}{$\begin{array}{r}\text { Angélica María Rosales } \\
\text { Doria I }\end{array}$} & & $\begin{array}{l}\text { Elaboración de } \\
\text { cronograma de } \\
\text { visitas a las sedes }\end{array}$ & $\begin{array}{l}\text { Planeación } \\
\text { estratégica } \\
\text { concertada }\end{array}$ & \\
\hline & \multirow{3}{*}{ Acción } & $\begin{array}{l}\text { Etapa 1: } \\
\text { ambientación } \\
\text { VICOM S-21 }\end{array}$ & Grupo Focal & 5 días \\
\hline \multirow[t]{9}{*}{$\begin{array}{r}\text { Juan Carlos Giraldo } \\
\text { Cardozo I }\end{array}$} & & $\begin{array}{l}\text { Etapa 2: } \\
\text { implementación } \\
\text { VICOM S-21 }\end{array}$ & $\begin{array}{l}\text { Entrevista } \\
\text { estructurada } \\
\text { Observación }\end{array}$ & 80 días \\
\hline & & $\begin{array}{l}\text { Etapa 3: } \\
\text { evaluación } \\
\text { VICOM S-21 }\end{array}$ & $\begin{array}{l}\text { Entrevistas } \\
\text { semiestructuradas }\end{array}$ & 8 días \\
\hline & \multirow{3}{*}{$\begin{array}{l}\text { Observa- } \\
\text { ción }\end{array}$} & $\begin{array}{l}\text { Etapa 1: } \\
\text { ambientación } \\
\text { VICOM S-21 }\end{array}$ & Grupo Focal & 5 días \\
\hline & & $\begin{array}{l}\text { Etapa 2: } \\
\text { implementación } \\
\text { VICOM S-21 }\end{array}$ & Observación & 80 días \\
\hline & & $\begin{array}{l}\text { Etapa 3: } \\
\text { evaluación } \\
\text { VICOM S-21 }\end{array}$ & $\begin{array}{l}\text { Entrevistas } \\
\text { semiestructuradas }\end{array}$ & 8 días \\
\hline & \multirow{4}{*}{ Reflexión } & $\begin{array}{l}\text { Análisis de la } \\
\text { información }\end{array}$ & \multirow{4}{*}{ Diálogo reflexivo } & \multirow{4}{*}{30 días } \\
\hline & & $\begin{array}{l}\text { Contrastación de } \\
\text { teorías }\end{array}$ & & \\
\hline & & $\begin{array}{l}\text { Discusión grupo } \\
\text { coinvestigador }\end{array}$ & & \\
\hline & & $\begin{array}{l}\text { Replanteamiento } \\
\text { Metodología } \\
\text { VICOM S-21. }\end{array}$ & & \\
\hline
\end{tabular}

Fuente: elaboración propia (2018)

Tabla 4. Proceso investigativo: retroalimentación

\section{Ciclo 3: Retroalimentación}

\begin{tabular}{|c|c|c|c|}
\hline Fase & Acciones & $\begin{array}{l}\text { Técnica de } \\
\text { investigación }\end{array}$ & Tiempo \\
\hline \multirow[b]{2}{*}{ Planeación } & $\begin{array}{l}\text { Revisión de } \\
\text { literatura }\end{array}$ & $\begin{array}{l}\text { Gestión } \\
\text { documental }\end{array}$ & \multirow[b]{2}{*}{10 días } \\
\hline & $\begin{array}{l}\text { Diseño actividades } \\
\text { a adicionar a } \\
\text { la metodología } \\
\text { VICOM S-21 }\end{array}$ & Diálogo reflexivo & \\
\hline \multirow[t]{2}{*}{ Acción } & $\begin{array}{l}\text { Ajustes a la } \\
\text { metodología } \\
\text { VICOM S-21 } \\
\text { en la etapa de } \\
\text { implementación }\end{array}$ & Diálogo reflexivo & 4 días \\
\hline & $\begin{array}{l}\text { Elaboración de } \\
\text { la lista de nuevos } \\
\text { videojuegos }\end{array}$ & $\begin{array}{l}\text { Gestión } \\
\text { documental }\end{array}$ & 2 días \\
\hline \multirow[t]{2}{*}{$\begin{array}{l}\text { Observa- } \\
\text { ción }\end{array}$} & $\begin{array}{l}\text { Ajustes a la } \\
\text { metodología } \\
\text { VICOM S-21 } \\
\text { en la etapa de } \\
\text { implementación }\end{array}$ & Diálogo reflexivo & 4 días \\
\hline & $\begin{array}{l}\text { Elaboración de } \\
\text { la lista de nuevos } \\
\text { videojuegos }\end{array}$ & Diálogo reflexivo & 2 días \\
\hline
\end{tabular}

Ciclo 3: Retroalimentación

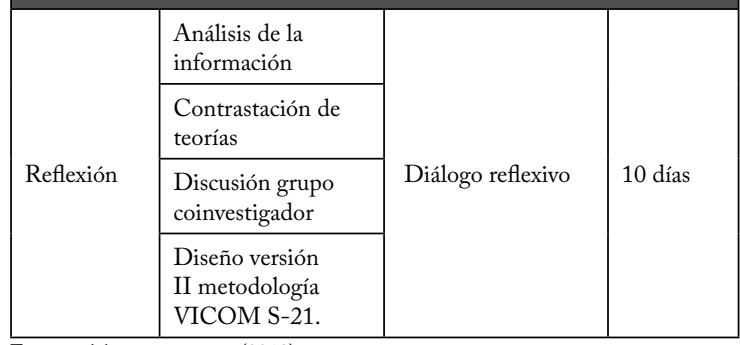

Fuente: elaboración propia (2018)

\section{RESULTADOS}

Ciclo 1: propuesta de acciones y estrategias: en este ciclo se ejecutaron tres actividades: un primer acercamiento con docentes y estudiantes, en donde se realizó la sensibilización acerca de lo que se lograría con el proyecto y la forma como los docentes y estudiantes de las sedes multigrado de la Institución Educativa Mariscal Sucre podían ser parte activa del mismo; se obtuvo información acerca de las técnicas y estrategias didácticas utilizadas por los docentes en sus clases, se indagó sobre qué habilidades consideraban necesarias para desempeñar bien cualquier trabajo y sus conceptos y opiniones acerca de la utilización de herramientas TIC, como los videojuegos. Luego se realizó un conversatorio que surgió a raíz de los vacíos existentes por parte de los docentes en cuanto a competencias del siglo XXI y la necesidad de trabajar estas en el aula de clases; se identificaron cada una de estas competencias según ATCS21S, que las define en once habilidades en cuatro grandes categorías: maneras de pensar (creatividad e innovación, pensamiento crítico, resolución de problemas $\mathrm{y}$ aprender a aprender); herramientas para trabajar (apropiación de las tecnologías digitales y manejo de la información); maneras de trabajar (comunicación y colaboración), y maneras de vivir en el mundo (vida y carrera, responsabilidad personal y social y ciudadanía local y global); y, finalmente, se realizó una tercera actividad para cerrar el ciclo, en donde se reunieron nuevamente los docentes y los investigadores y se discutió sobre qué estrategias, utilizando videojuegos, se podrían planear e implementar para desarrollar en los estudiantes de sedes multigrados para desarrollar competencias del siglo XXI. 
Después de analizar la información recolectada en cada una de las actividades realizadas y de contrastar las teorías de diversos autores relacionadas con el tema objeto de estudio, se elaboró una propuesta metodológica que recoge los aportes de los docentes coinvestigadores. Cabe anotar que dicha propuesta fue socializada con los docentes participantes; después de una discusión se realizaron algunos ajustes, se avaló por los mismos y se le dio como nombre metodología VICOM-S21.

Ciclo 2: formalización y aplicación: en este ciclo, luego de conversar con el grupo de docentes participantes y mostrarles una serie de videojuegos, se seleccionaron para la aplicación de la propuesta: Stickman Warriors, Subway Surfers, Fast Racing, Color Switch, Banana Kong, Beach Buggy Racing, Slither.io, Gravity switch, Rodeo Stampede, Geometry Dash, Minecraft, Temple Run 2, puesto que estos presentan características como facilidad de acceso, descarga y navegación, aptos para todo público, interfaz amigable, diseño acorde con los usuarios (niños entre 5 y 12 años), compatibilidad con tabletas electrónicas de sistema Android y popularidad. Posteriormente se realizó la aplicación de la Metodología VICOM S-21, la cual se compone de tres etapas: ambientación, implementación y evaluación.

Etapa 1. Ambientación: en esta etapa se proyectaron escenas de los videojuegos seleccionados con el fin de centrar la atención del estudiante, despertar su curiosidad, motivarlo a participar, a interesarse en experimentar nuevos retos y a desarrollar nuevas habilidades; después de la proyección se realizaron una serie de preguntas, las cuales permitieron conocer los pensamientos de los estudiantes acerca de qué es un videojuego, qué se busca jugándolo, qué hay que hacer para ganar, qué se puede aprender por medio de estos, qué les parece utilizarlos en el aula de clases como una herramienta para aprender y si les gusta la idea de participar en un proyecto donde se utilicen videojuegos para desarrollar diferentes competencias. Es de resaltar que todos los estudiantes tienen claro qué es un videojuego y lo expresan diciendo que son imágenes en movimiento que se manipulan para alcanzar una meta, que utilizando videojuegos se divierten, se entretienen, aprenden, crean cosas, están tranquilos, están felices; también aciertan al mencionar que todo videojuego tiene un propósito, que es llegar a una meta venciendo obstáculos y pasando diferentes niveles, donde cada uno de estos tiene un grado de complejidad.

Etapa 2. Implementación: la implementación consta de tres actividades, una en donde se realiza con los estudiantes un trabajo individual orientado por los investigadores y su grupo de apoyo; otra actividad de trabajo individual libre y, finalmente, una actividad de trabajo en equipo. En la actividad 1 se propone un descubrimiento guiado, en el cual el docente proporciona su dirección, expone una meta a ser alcanzada y le da la oportunidad al estudiante de explorar los doce videojuegos seleccionados previamente; esta exploración permite a los estudiantes familiarizarse con ellos, activar conocimientos y destrezas necesarias para jugar y elegir sus preferencias a partir de la identificación de las características de cada uno. En esta actividad el tiempo no fue suficiente para que el estudiante pudiera interactuar con videojuegos de compleja jugabilidad, por lo cual es preciso anotar que los tipos de videojuegos de mayor aceptación por los niños participantes en esta investigación fueron los de tipo plataforma y deportivos de jugabilidad simple; los factores que determinaron la escogencia de estos videojuegos fue el rango de edades en las que oscilan estos niños, que es de 5 a 12 años aproximadamente, y la poca interacción que tenían con dispositivos electrónicos antes de iniciar la investigación.

La segunda actividad fue un trabajo individual libre, en donde cada estudiante tenía la oportunidad de jugar con máximo cinco videojuegos de su predilección en un período de dos horas de su jornada escolar, durante dos días a la semana en el transcurso de un mes; se determinó un tope al número de videojuegos, teniendo en cuenta la disponibilidad de tiempo de los docentes para el desarrollo de la actividad. Al empezar la sesión, cada estudiante inició a jugar principalmente con aquel videojuego que les resultaba muy fácil, pues podía obtener mayores puntajes que en aquellos en los cuales no sabía su manipulación, observándose claramente
Competencias del siglo XXI: ¿cómo desarrollarlas mediante el uso de videojuegos en un contexto multigrado?

I Panorama

I pp. 7-17

I Volumen 12

I Número 23

I Julio - Diciembre I 2018 
Yennis Cristina Lozano

Abad I

Angélica María Rosales Doria I

Juan Carlos Giraldo

Cardozo I

Panorama I

pp. 7-17।

Volumen 12 I

Número 23 I

Julio - Diciembre I

2018 I

ISSN Impreso

1909-7433 I

ISSN en línea 2145-308X I

12 que escogían los videojuegos principalmente por el nivel de complejidad al manejarlo y no por el tipo de videojuego que era; sin embargo, de forma autónoma exploraron las diferentes opciones para aprender a jugar otros de los videojuegos seleccionados, y en aquellos casos en donde se les dificultaba su manipulación, buscaron ayuda entre pares o con el equipo de apoyo, a pesar de ser un trabajo individual.

Finalmente, en la actividad 3 se realizó un trabajo en equipo, se agrupó a los estudiantes teniendo en cuenta la población estudiantil de las sedes educativas; cada grupo fue conformado por niños de diferentes grados; a cada integrante se le entregó una tableta electrónica con el mismo videojuego instalado. Se les pidió que le dieran un nombre al equipo y que todos los integrantes llegaran a una meta específica, utilizando la estrategia que desearan; dicha meta fue propuesta por las investigadoras al momento de asignar el videojuego. Al finalizar la sesión, cada equipo escogió un relator que explicó las estrategias utilizadas para llegar a su meta. Esta actividad se realizó durante cinco sesiones, de tal manera que cada grupo trabajó con los cinco videojuegos que fueron escogidos por las investigadoras, teniendo en cuenta la información suministrada en el formato acerca de las preferencias en videojuegos de cada estudiante, en donde ellos ordenaron del 1 al 12 sus favoritos, siendo el primero el de mayor predilección. En la modalidad de trabajo en equipo se observó que aquel estudiante que alcanzaba la meta propuesta primero que sus compañeros de equipo, se disponía a colaborarle a los otros con el fin de que todos alcanzaran dicho objetivo; en la mayoría de los casos, estos estudiantes eran los de grados superiores $\left(4^{\circ}\right.$ o $5^{\circ}$ ), y aquel estudiante que encontraba las técnicas para jugar de forma rápida se las decía a sus compañeros. También se observó que había un estudiante en cada equipo que hacía las veces de líder y motivaba a los otros a alcanzar la meta. Hay que mencionar, además, que en las sedes de Villa Aideé y Veracruz, para intentar resolver problemas relacionados con el tiempo estipulado para jugar determinado videojuego, debido a que no avanzan en los niveles del mismo, los estudiantes se intercambiaban el dispositivo, de tal manera que aquel que estuviera en desventaja pudiera seguir jugando con otra tableta, mientras el compañero con mayor habilidad le despejaba el camino para alcanzar el siguiente nivel.

Etapa 3. Evaluación de la metodología: luego de ejecutar las actividades propuestas, se tuvieron en cuenta ciertas sugerencias realizadas por docentes y estudiantes participantes de la investigación, tales como adicionar más tiempo para la aplicación de las actividades, debido a que los estudiantes no pudieron interactuar lo suficiente con videojuegos de compleja jugabilidad; agregar actividades donde se trabajara con grupos homogéneos, ya que se notó que estudiantes de grados inferiores tenían menor interacción con los videojuegos, puesto que los mayores ejercían cierta autoridad sobre los menores y, por lo tanto, si los pequeños querían alcanzar la meta propuesta debían ceder parte de su tiempo de juego y agregar dentro del grupo de videojuegos alguno de tipo multijugador que les permitiera interactuar con dos o más compañeros en el mismo juego al mismo tiempo.

Ciclo 3: retroalimentación: luego de la formalización y aplicación de la metodología VICOM S-21 y de la observación de dicha aplicación, se efectuó una evaluación que permitió realizar algunos ajustes sugeridos por los docentes y estudiantes participantes, dando como resultado una nueva versión de la metodología propuesta. Las siguientes tablas muestran las evidencias encontradas a partir de las observaciones realizadas en la etapa de implementación de la propuesta y los indicadores que permitieron determinar a partir de esa evidencia que la metodología VICOM S-21 fomenta el desarrollo de competencias para el siglo XXI. 
Tabla 5. Resumen evidencia-teoría relacionada con competencia creatividad e innovación

\begin{tabular}{|c|c|c|c|}
\hline Competencia & Indicador & Evidencia & $\begin{array}{l}\text { Teoría } \\
\text { Relacionada }\end{array}$ \\
\hline \multirow{3}{*}{ 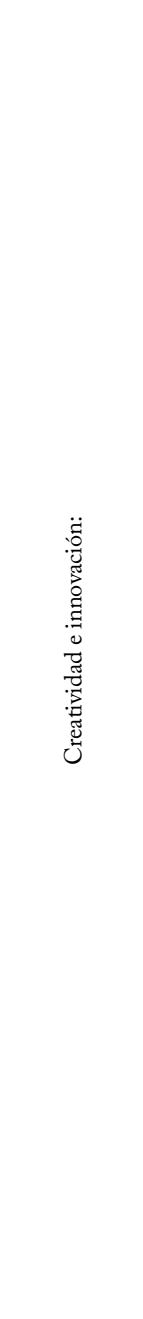 } & $\begin{array}{l}\text { Genera } \\
\text { ideas } \\
\text { originales. }\end{array}$ & $\begin{array}{l}\text { Al no avanzar en } \\
\text { los niveles de los } \\
\text { videojuegos para llegar } \\
\text { a la meta propuesta, } \\
\text { los estudiantes se } \\
\text { intercambiaban la } \\
\text { tableta, de tal manera } \\
\text { que aquel que no } \\
\text { avanzaba pudiera } \\
\text { seguir jugando con } \\
\text { otra tableta mientras el } \\
\text { compañero con mayor } \\
\text { habilidad le ayudaba } \\
\text { a alcanzar el siguiente } \\
\text { nivel. }\end{array}$ & \multirow{3}{*}{$\begin{array}{l}\begin{array}{l}\text { Según } \\
\text { ATC21S }\end{array} \\
\text { Creatividad } \\
\text { e } \\
\text { innovación: } \\
\text { capacidad } \\
\text { para generar } \\
\text { ideas } \\
\text { originales } \\
\text { que tengan } \\
\text { valor en la } \\
\text { actualidad, } \\
\text { interpretar } \\
\text { de distintas } \\
\text { formas las } \\
\text { situaciones } \\
\text { y visualizar } \\
\text { una variedad } \\
\text { de respuestas } \\
\text { ante un } \\
\text { problema o } \\
\text { circunstancia. }\end{array}$} \\
\hline & $\begin{array}{l}\text { Interpreta } \\
\text { de distintas } \\
\text { formas las } \\
\text { situaciones. }\end{array}$ & $\begin{array}{l}\text { Cada estudiante } \\
\text { inicia a jugar con } \\
\text { aquel videojuego que } \\
\text { le resulta muy fácil, } \\
\text { pues puede obtener } \\
\text { mayores puntajes } \\
\text { que en aquellos en } \\
\text { los cuales no sabe su } \\
\text { manipulación; sin } \\
\text { embargo, exploran las } \\
\text { diferentes opciones } \\
\text { para aprender a jugar } \\
\text { con otros de los } \\
\text { videojuegos. }\end{array}$ & \\
\hline & $\begin{array}{l}\text { Visualiza } \\
\text { una } \\
\text { variedad de } \\
\text { respuestas } \\
\text { ante un } \\
\text { problema. }\end{array}$ & $\begin{array}{l}\text { En aquellos casos } \\
\text { en donde se les } \\
\text { dificultaba la } \\
\text { manipulación de los } \\
\text { juegos, y para intentar } \\
\text { resolver problemas } \\
\text { relacionados con el } \\
\text { tiempo estipulado para } \\
\text { jugar determinado } \\
\text { videojuego, buscaron } \\
\text { ayuda entre pares } \\
\text { o con el equipo } \\
\text { de apoyo, aunque } \\
\text { el trabajo fuera } \\
\text { individual. }\end{array}$ & \\
\hline
\end{tabular}

Fuente: elaboración propia (2018)

Tabla 6. Resumen evidencia-teoría relacionada con competencia pensamiento crítico

\begin{tabular}{|c|c|c|c|}
\hline Competencia & Indicador & Evidencia & $\begin{array}{l}\text { Teoría } \\
\text { Relacionada }\end{array}$ \\
\hline $\begin{array}{l}\text { Pensamiento } \\
\text { crítico: }\end{array}$ & $\begin{array}{l}\text { Interpreta, } \\
\text { analiza, } \\
\text { evalúa, hace } \\
\text { inferencias, } \\
\text { explica y } \\
\text { clarifica } \\
\text { significados. }\end{array}$ & $\begin{array}{l}\text { Al realizar la } \\
\text { evaluación de } \\
\text { la metodología, } \\
\text { los estudiantes } \\
\text { son capaces de } \\
\text { analizar, evaluar } \\
\text { todo el proceso } \\
\text { realizado durante } \\
\text { la aplicación de } \\
\text { las actividades } \\
\text { y explicar las } \\
\text { fortalezas y } \\
\text { debilidades } \\
\text { encontradas por } \\
\text { ellos durante el } \\
\text { proceso. }\end{array}$ & $\begin{array}{l}\begin{array}{l}\text { Según } \\
\text { ATC21S }\end{array} \\
\text { Pensamiento } \\
\text { crítico: } \\
\text { capacidad de } \\
\text { interpretar, } \\
\text { analizar, } \\
\text { evaluar, hacer } \\
\text { inferencias, } \\
\text { explicar y } \\
\text { clarificar } \\
\text { significados. }\end{array}$ \\
\hline
\end{tabular}

Tabla 7. Resumen evidencia-teoría relacionada con competencia resolución de problemas

\begin{tabular}{|c|c|c|c|}
\hline Competencia & Indicador & Evidencia & $\begin{array}{l}\text { Teoría } \\
\text { Relacionada }\end{array}$ \\
\hline $\begin{array}{l}\text { Resolución de } \\
\text { problemas }\end{array}$ & $\begin{array}{l}\text { Plantea } \\
\text { y analiza } \\
\text { problemas } \\
\text { para } \\
\text { generar } \\
\text { alternativas } \\
\text { de solución } \\
\text { eficaces y } \\
\text { viables. }\end{array}$ & $\begin{array}{l}\text { El pensar } \\
\text { estratégicamente } \\
\text { sorteando } \\
\text { obstáculos al jugar } \\
\text { con videojuegos y } \\
\text { tomar decisiones } \\
\text { acerca de una } \\
\text { técnica u otra para } \\
\text { poder alcanzar } \\
\text { determinado nivel } \\
\text { o meta. } \\
\text { Al experimentar } \\
\text { el fracaso en } \\
\text { las estrategias } \\
\text { planteadas } \\
\text { para llegar a } \\
\text { determinada meta, } \\
\text { replanteaban un } \\
\text { plan de acción para } \\
\text { poder lograr el } \\
\text { objetivo. }\end{array}$ & $\begin{array}{l}\text { Según } \\
\text { ATC21S. } \\
\text { Resolución de } \\
\text { problemas: } \\
\text { capacidad } \\
\text { de plantear } \\
\text { y analizar } \\
\text { problemas } \\
\text { para generar } \\
\text { alternativas } \\
\text { de soluciones } \\
\text { eficaces y } \\
\text { viables. }\end{array}$ \\
\hline
\end{tabular}

Fuente: elaboración propia (2018)

Tabla 8. Resumen evidencia-teoría relacionada con competencia aprender a aprender

\begin{tabular}{|l|l|l|l|}
\hline Competencia & Indicador & Evidencia & $\begin{array}{l}\text { Teoría } \\
\text { Relacionada }\end{array}$ \\
\hline $\begin{array}{l}\text { Aprender a } \\
\text { aprender }\end{array}$ & $\begin{array}{l}\text { Conoce, } \\
\text { organiza y } \\
\text { auto-re- } \\
\text { gula su } \\
\text { propio } \\
\text { proceso de } \\
\text { aprendi- } \\
\text { zaje. }\end{array}$ & $\begin{array}{l}\text { Al trabajar de forma } \\
\text { individual, sintiéndose } \\
\text { libre de escoger } \\
\text { los videojuegos de } \\
\text { su preferencia y } \\
\text { dedicando a cada uno } \\
\text { de estos el tiempo que } \\
\text { considerara necesario, } \\
\text { está autorregulando su } \\
\text { aprendizaje. }\end{array}$ & $\begin{array}{l}\text { Según } \\
\text { ATC21S } \\
\text { capacidad } \\
\text { de conocer, } \\
\text { organizar y } \\
\text { auto-regular } \\
\text { el propio } \\
\text { aproceso de } \\
\text { aprendizaje. }\end{array}$ \\
& $\begin{array}{l}\text { Había un estudiante } \\
\text { en cada equipo que } \\
\text { hacía las veces de } \\
\text { líder, el cual motivaba } \\
\text { a los otros a alcanzar } \\
\text { la meta. }\end{array}$ & \\
\hline
\end{tabular}

Fuente: elaboración propia (2018)

Tabla 9. Resumen evidencia-teoría relacionada con competencia apropiación de las tecnologías digitales

\begin{tabular}{|c|c|c|c|}
\hline Competencia & Indicador & Evidencia & $\begin{array}{l}\text { Teoría } \\
\text { Relacionada }\end{array}$ \\
\hline $\begin{array}{l}\text { Apropiación } \\
\text { de las } \\
\text { tecnologías } \\
\text { digitales }\end{array}$ & $\begin{array}{l}\text { Explora, } \\
\text { crea, se } \\
\text { comunica } \\
\text { y produce } \\
\text { utilizando } \\
\text { las tecnolo- } \\
\text { gías como } \\
\text { herramien- } \\
\text { tas. }\end{array}$ & $\begin{array}{l}\text { El uso continuo } \\
\text { del dispositivo } \\
\text { electrónico en todas } \\
\text { las actividades } \\
\text { permitió que los } \\
\text { estudiantes se } \\
\text { apropiaran de las } \\
\text { tecnologías digitales. }\end{array}$ & $\begin{array}{l}\text { Según el } \\
\text { Proyecto } \\
\text { ATC21S } \\
\text { Apropiación } \\
\underline{\text { de las }} \\
\text { tecnologías } \\
\text { digitales: } \\
\text { capacidad para } \\
\text { explorar, crear, } \\
\text { comunicarse } \\
\text { y producir } \\
\text { utilizando las } \\
\text { tecnologías } \\
\text { como } \\
\text { herramientas. }\end{array}$ \\
\hline
\end{tabular}

I Panorama

I pp. 7-17

I Volumen 12

I Número 23

I Julio - Diciembre

I 2018 


\section{Yennis Cristina Lozano}

Abad I

Angélica María Rosales

Doria I

Juan Carlos Giraldo

Cardozo I

Fuente: elaboración propia (2018)
Tabla 11. Resumen evidencia-teoría relacionada con la
Competencia comunicación
\begin{tabular}{|l|l|l|l|}
\hline Competencia & Indicador & Evidencia & $\begin{array}{l}\text { Teoría } \\
\text { Relacionada }\end{array}$ \\
\hline Comunicación & $\begin{array}{l}\text { Conoce su } \\
\text { lengua y la } \\
\text { utiliza en } \\
\text { una amplia } \\
\text { variedad de } \\
\text { situaciones } \\
\text { y mediante } \\
\text { diversos } \\
\text { medios. }\end{array}$ & $\begin{array}{l}\text { La interacción } \\
\text { constante entre } \\
\text { los estudiantes, el } \\
\text { grupo de apoyo y las } \\
\text { investigadoras permite } \\
\text { que se fortalezca } \\
\text { la seguridad, la } \\
\text { confianza y el respeto } \\
\text { para comunicarse. }\end{array}$ & $\begin{array}{l}\text { Según } \\
\text { ATC21S } \\
\text { Comunica- } \\
\text { ción: } \\
\text { capacidad } \\
\text { que abarca el } \\
\text { conocimiento } \\
\text { de la lengua } \\
\text { y la habilidad } \\
\text { para utilizarla } \\
\text { en una amplia } \\
\text { variedad de } \\
\text { situaciones } \\
\text { y mediante } \\
\text { diversos } \\
\text { medios. }\end{array}$ \\
\hline Fuente: elaboración propia (2018) & $\begin{array}{l}\text { Los estudiantes ha- } \\
\text { cían preguntas sobre } \\
\text { técnicas de juego y } \\
\text { palabras relacionadas } \\
\text { con los videojuegos; } \\
\text { esto permitió la } \\
\text { adquisición de un } \\
\text { vocabulario para } \\
\text { comunicarse entre } \\
\text { sí de acuerdo con el } \\
\text { contexto. }\end{array}$ & \\
\hline
\end{tabular}

Tabla 12. Resumen evidencia-teoría relacionada competencia Colaboración

\begin{tabular}{|c|c|c|c|c|}
\hline & Competencia & Indicador & Evidencia & $\begin{array}{l}\text { Teoría } \\
\text { Relacionada }\end{array}$ \\
\hline $\begin{array}{r}\text { Panorama I } \\
\text { pp. 7-17 I } \\
\text { Volumen } 12 \text { I } \\
\text { Número } 23 \text { I } \\
\text { - Diciembre I } \\
2018 \text { I } \\
\text { SSN Impreso } \\
\text { 1909-7433 I } \\
\text { SSN en línea } \\
2145-308 X \text { I }\end{array}$ & Colaboración & $\begin{array}{l}\text { Trabaja } \\
\text { de forma } \\
\text { efectiva } \\
\text { con otras } \\
\text { personas } \\
\text { para al- } \\
\text { canzar un } \\
\text { objetivo } \\
\text { común, } \\
\text { articu- } \\
\text { lando los } \\
\text { esfuerzos } \\
\text { propios } \\
\text { con los } \\
\text { de los } \\
\text { demás. }\end{array}$ & $\begin{array}{l}\text { Los estudiantes } \\
\text { buscan ayuda entre } \\
\text { pares o con el equipo } \\
\text { de apoyo, aunque el } \\
\text { trabajo sea individual. } \\
\text { Aquel estudiante que } \\
\text { alcanzaba la meta } \\
\text { propuesta primero que } \\
\text { sus compañeros de } \\
\text { equipo, se disponía a } \\
\text { colaborarle a los otros } \\
\text { con el fin de que todos } \\
\text { alcanzaran dicha meta. } \\
\text { El estudiante que } \\
\text { encontraba una técnica } \\
\text { para jugar de forma } \\
\text { rápida, se la decía al } \\
\text { compañero de equipo } \\
\text { para avanzar más rá- } \\
\text { pido en la consecución } \\
\text { de las metas. }\end{array}$ & $\begin{array}{l}\text { Según } \\
\text { ATC21S } \\
\text { Colaboración: } \\
\\
\text { capacidad de } \\
\text { trabajar de } \\
\text { forma efectiva } \\
\text { con otras } \\
\text { personas para } \\
\text { alcanzar un } \\
\text { objetivo común, } \\
\text { articulando } \\
\text { los esfuerzos } \\
\text { propios con los } \\
\text { de los demás. }\end{array}$ \\
\hline
\end{tabular}

Fuente: elaboración propia (2018)
Tabla 13. Resumen evidencia-teoría relacionada con competencia vida y carrera

\begin{tabular}{|c|c|c|c|}
\hline Competencia & Indicador & Evidencia & $\begin{array}{l}\text { Teoría } \\
\text { Relacionada }\end{array}$ \\
\hline \multirow[t]{2}{*}{ Vida y carrera } & $\begin{array}{l}\text { Planea y fija } \\
\text { metas. }\end{array}$ & $\begin{array}{l}\mathrm{Al} \text { asignarse roles } \\
\text { y responsabilidades } \\
\text { individuales en } \\
\text { las actividades de } \\
\text { trabajo en equipo }\end{array}$ & \multirow{2}{*}{$\begin{array}{l}\text { Según } \\
\text { ATC21S } \\
\text { Vida y carrera: } \\
\text { Abarca, por } \\
\text { ejemplo, } \\
\text { capacidades de } \\
\text { planeamiento } \\
\text { y fijación } \\
\text { de metas; } \\
\text { capacidades } \\
\text { para persistir } \\
\text { y sortear } \\
\text { obstáculos. }\end{array}$} \\
\hline & $\begin{array}{l}\text { Posee } \\
\text { capacidades } \\
\text { como la } \\
\text { tolerancia } \\
\text { a la } \\
\text { frustración, } \\
\text { el esfuerzo } \\
\text { y el diálogo } \\
\text { interno } \\
\text { positivo } \\
\text { para } \\
\text { persistir } \\
\text { y sortear } \\
\text { obstáculos } \\
\text { en el } \\
\text { camino. }\end{array}$ & $\begin{array}{l}\text { Al interesarse } \\
\text { en terminar las } \\
\text { actividades, a pesar } \\
\text { de las dificultades } \\
\text { en el uso del } \\
\text { dispositivo, ya } \\
\text { fuera por la falta de } \\
\text { competencias en su } \\
\text { manejo, problemas } \\
\text { de fluido eléctrico } \\
\text { y que en algunas } \\
\text { sedes no alcanzaban } \\
\text { los dispositivos. } \\
\text { Aprenden a esperar } \\
\text { su turno para la } \\
\text { utilización de las } \\
\text { tabletas cuando } \\
\text { estas no eran } \\
\text { suficientes para } \\
\text { todos. }\end{array}$ & \\
\hline
\end{tabular}

Fuente: elaboración propia (2018)

Tabla 14. Resumen evidencia-teoría relacionada con competencia responsabilidad personal y social

\begin{tabular}{|c|c|c|c|}
\hline Competencia & Indicador & Evidencia & $\begin{array}{l}\text { Teoría } \\
\text { Relacionada }\end{array}$ \\
\hline $\begin{array}{l}\text { Responsabili- } \\
\text { dad personal y } \\
\text { social }\end{array}$ & $\begin{array}{l}\text { Toma deci- } \\
\text { siones y actúa } \\
\text { pensando } \\
\text { aquello que } \\
\text { favorece el } \\
\text { bienestar } \\
\text { propio, de } \\
\text { otros y del } \\
\text { planeta, com- } \\
\text { prendiendo } \\
\text { la profunda } \\
\text { conexión que } \\
\text { existe entre } \\
\text { todos ellos. }\end{array}$ & $\begin{array}{l}\text { Los estudiantes } \\
\text { toman decisiones } \\
\text { al escoger los } \\
\text { videojuegos de su } \\
\text { preferencia. } \\
\text { Había un } \\
\text { estudiante en cada } \\
\text { equipo que hacía } \\
\text { las veces de líder, } \\
\text { el cual motivaba } \\
\text { a los otros a } \\
\text { alcanzar la meta. } \\
\text { Al planear } \\
\text { y aplicar las } \\
\text { estrategias } \\
\text { necesarias para } \\
\text { que su equipo } \\
\text { alcance la meta } \\
\text { propuesta en las } \\
\text { actividades. }\end{array}$ & $\begin{array}{l}\text { Según } \\
\text { ATC21S } \\
\text { Responsabili- } \\
\text { dad personaly } \\
\text { social: } \\
\text { toma decisiones } \\
\text { y actúa } \\
\text { considerando } \\
\text { aquello que } \\
\text { favorece el } \\
\text { bienestar } \\
\text { propio, de otros } \\
\text { y del planeta, } \\
\text { comprendiendo } \\
\text { la profunda } \\
\text { conexión que } \\
\text { existe entre } \\
\text { todos ellos. }\end{array}$ \\
\hline
\end{tabular}

Fuente: elaboración propia (2018) 
Tabla 15. Resumen evidencia-teoría relacionada con competencia ciudadanía local y global

\begin{tabular}{|c|c|c|c|}
\hline Competencia & Indicador & Evidencia & $\begin{array}{l}\text { Teoría } \\
\text { Relacionada }\end{array}$ \\
\hline $\begin{array}{l}\text { Ciudadanía } \\
\text { local y global }\end{array}$ & $\begin{array}{l}\text { Asume un } \\
\text { rol activo, } \\
\text { reflexivo y } \\
\text { constructivo } \\
\text { en la comu- } \\
\text { nidad local, } \\
\text { nacional } \\
\text { y global, } \\
\text { comprome- } \\
\text { tiéndose con } \\
\text { el cumpli- } \\
\text { miento de } \\
\text { los derechos } \\
\text { humanos y } \\
\text { de los valores } \\
\text { éticos univer- } \\
\text { sales. }\end{array}$ & $\begin{array}{l}\text { Para los equipos } \\
\text { era un gran logro } \\
\text { alcanzar la meta } \\
\text { y se notaba en las } \\
\text { celebraciones de } \\
\text { los integrantes, } \\
\text { quienes brincaban, } \\
\text { aplaudían y hasta } \\
\text { se demostraban } \\
\text { afecto por medio de } \\
\text { abrazos. } \\
\text { Las actividades } \\
\text { con videojuegos en } \\
\text { el aula permiten } \\
\text { que los alumnos } \\
\text { se enfrenten a } \\
\text { situaciones de } \\
\text { competencia, donde } \\
\text { se evidencian } \\
\text { sus valores y } \\
\text { contribuyen en su } \\
\text { formación como un } \\
\text { ser integro. }\end{array}$ & $\begin{array}{l}\begin{array}{l}\text { Según } \\
\text { ATC21S }\end{array} \\
\text { Ciudada- } \\
\text { nía local y } \\
\text { global: } \\
\text { capacidad } \\
\text { de asumir } \\
\text { un rol activo, } \\
\text { reflexivo y } \\
\text { constructivo } \\
\text { en la comu- } \\
\text { nidad local, } \\
\text { nacional } \\
\text { y global, } \\
\text { comprome- } \\
\text { tiéndose con } \\
\text { el cumpli- } \\
\text { miento de } \\
\text { los derechos } \\
\text { humanos } \\
\text { y de los } \\
\text { valores éticos } \\
\text { universales. }\end{array}$ \\
\hline
\end{tabular}

\section{CONCLUSIONES}

Luego de determinar estrategias y acciones que involucraron el uso de videojuegos para fomentar el desarrollo de competencias del siglo XXI en un contexto de formación multigrado, aplicar la metodología VICOM S-21 y finalmente analizar los cambios, ventajas y limitaciones que se evidencian después de la aplicación de esta, se llega a las siguientes conclusiones:

La heterogeneidad de los estudiantes en los grupos multigrados hace necesario que al trabajar con estos se encaucen las prácticas tradicionales de enseñanza hacia estrategias innovadoras y flexibles (Colbert, 1999; Vargas, 2003; Bustos, 2010), como es el caso del uso de videojuegos, aprendizaje cooperativo, aprendizaje autónomo, entre otras; que vayan de la mano con las exigencias de la sociedad actual y los gustos e intereses de los estudiantes. $\mathrm{Al}$ respecto, Morales (2009) plantea que la utilización de los videojuegos como herramientas en las escuelas responde a una necesidad de uso, ya que la mayoría de los estudiantes participan activamente en este tipo de actividad de forma habitual. De igual forma, Gómez del Castillo (2007) expone que los videojuegos potencian en los jóvenes algunas habilidades tales como memorización, percepción y reconocimiento espacial, descubrimiento inductivo, razonamiento lógico, comprensión lectora, vocabulario, resolución de problemas, planificación de estrategias, autocontrol, autoevaluación, motivación, instinto de superación, curiosidad e inquietud por investigar, habilidades sociales, competencias TIC, entre otras.

La metodología VICOM-S21 es una propuesta educativa que se orienta hacia la incorporación de los videojuegos en el aula de clases, entendiendo sus beneficios pedagógicos, dado que al ser utilizados con una intencionalidad educativa dejan de ser solamente una herramienta para jugar y se transforman en un medio que fomenta el desarrollo de competencias del siglo XXI, las cuales, según ATC21S (2015), son necesarias para que los estudiantes de hoy se conviertan en trabajadores y ciudadanos efectivos del mañana.

Una de las estrategias propuestas por el grupo de docentes investigadores está enmarcada en la modalidad de trabajo individual libre, donde al permitir a los estudiantes escoger los videojuegos se crea un ambiente donde estos se sienten en confianza y actúan naturalmente al trabajar sin sentirse obligados, lo que confirma lo expuesto por Charms (como se cita en Tapia, 2005). Una segunda estrategia propone un descubrimiento guiado en el cual el docente proporciona su dirección, expone una meta a ser alcanzada y le da la oportunidad al estudiante de explorar videojuegos seleccionados previamente para que este decida y aprenda a partir de su propia experiencia. La exploración de los diferentes videojuegos permitió a los estudiantes familiarizarse con estos, activar conocimientos y destrezas necesarias para jugar y elegir sus preferencias, lo cual confirma lo expuesto en la teoría de aprendizaje por descubrimiento de Jerome Bruner, en donde afirma que el estudiante debe descubrir su conocimiento y organizarlo en su estructura cognitiva mediante los distintos niveles de representación, lo cual indica que se genera un nuevo conocimiento al transformar la información que incorpora de su experiencia (Quaaz y Crespo, 2003).

Es de destacar que la metodología VICOM-S21 toma como referente la clasificación de competencias del siglo XXI propuesta por el
Competencias del siglo $\mathrm{XXI}$ : ¿cómo desarrollarlas mediante el uso

de videojuegos en un contexto multigrado?

I Panorama

I pp. 7-17

I Volumen 12

I Número 23

I Julio - Diciembre I 2018 
Yennis Cristina Lozano

Abad I

Angélica María Rosales Doria I

Juan Carlos Giraldo

Cardozo I

Panorama I

pp. 7-17।

Volumen 12 I

Número 23 ।

Julio - Diciembre I

2018 |

ISSN Impreso 1909-7433।

ISSN en línea 2145-308X I

1

16 proyecto ATC21S, el cual las agrupa en cuatro categorías: maneras de pensar (creatividad e innovación, pensamiento crítico, resolución de problemas, aprender a aprender); herramientas para trabajar (apropiación de las tecnologías digitales, manejo de la información); maneras de trabajar (comunicación, colaboración), y maneras de vivir en el mundo (vida y carrera, responsabilidad personal y social, ciudadanía local y global). Las evidencias encontradas a partir de las observaciones realizadas en la etapa de implementación de la propuesta, y el contraste de estas con los indicadores que surgen a partir de lo planteado por el proyecto ATC21S permitieron determinar que la metodología VICOM S-21 fomenta el desarrollo de competencias del siglo XXI, pero no determina un nivel o grado de desarrollo para cada una de estas.

Luego de la aplicación de las estrategias trazadas en la metodología VICOM-S21, se puede afirmar que para los estudiantes de las diferentes sedes multigrados de la Institución Educativa Mariscal Sucre, la utilización de videojuegos en el aula de clases se convierte en una forma de aprender de manera divertida, entretenida, de relajarse mientras aprenden, en donde crean cosas, están tranquilos y se concentran; además, adquieren paciencia, la habilidad para vencer obstáculos y así llegar a una meta, a incrementar su imaginación y a utilizar dispositivos electrónicos, confirmando así el potencial educativo de los videojuegos y su incidencia en el desarrollo de habilidades indispensables para desenvolverse como ciudadano del siglo XXI (Ellis, 2006; Galarneau, 2006).

Cabe señalar que los tipos de videojuegos de mayor aceptación por los niños participantes en esta investigación, fueron los de tipo plataforma y deportivos de jugabilidad simple; lo anterior debido a que las edades de los estudiantes oscilan entre los 5 y 12 años aproximadamente, y a la poca interacción que tenían con dispositivos electrónicos antes de iniciar la investigación; sin embargo, de forma autónoma exploraron las diferentes opciones para aprender a jugar otros tipos de videojuegos, adaptándose y avanzando a su propio ritmo, y en aquellos casos en donde se les dificultó su manipulación, buscaron ayuda entre pares.
Las estrategias apoyadas en videojuegos donde los estudiantes trabajan en equipo permiten una mayor interacción entre estudiantes, sin importar su edad o nivel académico, los incitan a compartir experiencias y a mejorar las relaciones interpersonales, y los integran para lograr un objetivo común. Hay que mencionar, además, que las actividades con videojuegos en el aula permiten que los alumnos se enfrenten a situaciones de competencia donde se evidencian sus valores y contribuyen en su formación como un ser íntegro. Esto muestra los cuatro principios fundamentales del aprendizaje cooperativo expuestos por Kagan y Kagan, (1994).

Por otro lado, es necesario recalcar que la investigación transformó las prácticas cotidianas de trabajo en el aula de los docentes coinvestigadores, las cuales se percibían monótonas y sin hacer uso de las herramientas TIC con las que contaban las sedes, y les permitió reflexionar sobre la necesidad de utilizar y crear estrategias innovadoras y flexibles en ese contexto de formación. Se evidenció un notable cambio en la actitud de los docentes coinvestigadores, mostrando aceptación a la utilización de las TIC y a la participación en proyectos que las involucren, confirmando lo expuesto por Esteban (2003), en relación a que aquellas prácticas donde se involucren las personas implicadas en una problemática y participen de forma colaborativa, reflexionando acerca de las necesidades y vivencias, cambian su realidad.

Esta investigación está altamente relacionada con los estándares propuestos a nivel internacional con respecto a las competencias que deben desarrollarse para que los jóvenes sean trabajadores efectivos y ciudadanos en la sociedad del conocimiento del siglo XXI, así como a la primera línea de investigación propuesta por el Plan Nacional de Ciencia y Tecnología propuesto por Colciencias desde 2017 hasta 2022, la cual expresa a la gamificación como "el uso de mecanismos de juego para impulsar la participación en escenarios que no son juegos y para cambiar comportamientos en un público objetivo con el fin de lograr resultados". Además, sienta las bases fundamentales para el desarrollo de estudios que faciliten la utilización de metodologías mediadas por TIC, apoyadas 
por referentes internacionales que desarrollen competencias en contextos educativos cuya naturaleza exija la innovación didáctica e intervenciones pedagógicas sistemáticas $\mathrm{y}$ desafiantes.

\section{REFERENCIAS}

1. Ananiadou, K. y Claro, M. (2010). Habilidades y competencias del siglo XXI para los aprendices del nuevo milenio en los paises de la OCDE. Recuperado de: http://recursostic. educacion.es/blogs/europa/media/ blogs/europa/informes/Habilidades_y_ competencias_siglo21_OCDE.pdf.

2. ATC21S. (2015). ATC21S. Recuperado de http://www.atc21s.org/

3. Bustos, A. (2010). Aproximación a las aulas de escuela rural: heterogeneidad y aprendizaje en los grupos multigrado. Revista de Educación, (352), 353-378.

4. Colbert, V. (1999). Mejorando el acceso y la calidad de la educación para el sector rural pobre. El caso de la Escuela Nueva en Colombia. Revista Iberoamericana de Educación, (20), 107-135.

5. Colciencias. (2016). Plan Nacional de Ciencia, Tecnología e Innovación para el desarrollo del sector de las Tecnologías de la Información y las Comunicaciones (TIC). Recuperado de http://www.colciencias. gov.co/sites/default/files/plan-cteitic-2017-2022_0.pdf

6. Eguia, J., Contreras, R. y Solano, L. (2012). Videojuegos: conceptos, historia y su potencial como herramienta para la educación. 3C TIC, (2), 1-14.

7. Ellis, H, Heppell, S., Kirriemuir, J., Krotoski, A., y McFarlane, A. (2006). Unlimited Learning: Computer and Video Games in the Learning Landscape. Technical Report, Entertainment and Leisure Software Publishers Association and Press enquiries.

8. Esteban, M. (2003). Investigación cualitativa en educación. Fundamentos y tradiciones. Madrid: Mc Graw and Hill Interamericana.
9. Ferrer, M. y Ruiz, J. (2005). Uso de videojuegos en niños de 7 a 12 años. Una aproximación mediante encuesta. Revista de Comunicación y Nuevas tecnologias, 4(1), 205-216.

10. Galarneau, L. y Zibit, M. (2006). Online Games for 21^st Century Skills. Ulearn, (6), 58.

11. Gee, J. (2004). Lo que nos enseñan los videojuegos sobre el aprendizaje y el alfabetismo. Archidona, España: Aljibe.

12. Gómez del Castillo, M. (2007). Videojuegos y transmisión de valores. Revista Iberoamericana de comunicación, 43(6), 1-10.

13. Kagan, S. y Kagan, S. (1994). Cooperative learning. San Juan Capistrano: Kagan Cooperative Learning.

14. Latorre, A. (2007). La investigación-acción: conocer y cambiar la práctica educativa. Barcelona: Graó de IRIF, SL.

15. Levis, D. (2013). Los videojuegos, un fenómeno de masas. Buenos Aires: Sivel.

16. Ley $\mathrm{N}^{\circ} 115$. (1994). Ley general de educación de la República de Colombia. Bogotá, Colombia.

17. Morales, E. (2009). El uso de los videojuegos como recurso de aprendizaje en educación primaria y Teoría de la $\mathrm{Co}_{-}$ municación. Diálogos de la comunicación, (78), 7.

18. Quaas, C. y Crespo, N. (2003). ¿Inciden los métodos de enseñanza del profesor en el desarrollo del conocimiento metacomprensivo de sus alumnos? Revista signos, 36(54), 225-234.

19. Tapia, J. (2005). Motivación para el aprendizaje: la perspectiva de los alumnos. Madrid: MEC.

20.Vargas, T. (2003). Escuelas multigrados: ¿Cómo funcionan? Reflexión a partir de la experiencia evaluativa del proyecto Escuelas Multigrado-Innovadas. República Dominicana: Editora de Colores S.A. Recuperado de: http://unesdoc. unesco. org/images/0013/001374/137497so. pdf.
Competencias

del siglo XXI:

¿cómo desarrollarlas

mediante el uso

de videojuegos

en un contexto

multigrado?
I Panorama

I pp. 7-17

I Volumen 12

I Número 23

I Julio - Diciembre

I 2018

17 